\title{
Flow Diversion for Ophthalmic Artery Aneurysms
}

\author{
(D)A.M. Burrows, (D). Brinjikji, (D) R.C. Puffer, (D). Cloft, DD.F. Kallmes, and (D) G. Lanzino
}

\begin{abstract}
SUMMARY: Endovascular treatments of ophthalmic segment aneurysms are commonly used but visual outcomes remain a concern. We performed a retrospective review of patients with carotid-ophthalmic aneurysms treated with flow diversion from June 2009 to June 2015. The following outcomes were studied through chart review: visual outcomes, complications, postoperative stroke and intraparenchymal hemorrhage, and clinical outcomes. Angiographic outcomes were studied with angiography and MRA at 6 months, 1 year, and 3 years. We evaluated 50 carotid-ophthalmic aneurysms in 48 patients, among whom 44 patients with 46 aneurysms underwent treatment. The mean clinical follow-up was $29 \pm 22$ months (range, 0-65 months). There were no permanent adverse visual outcomes. There was 1 death because of late intraparenchymal hemorrhage (2.2\%). Six-month angiography showed complete occlusion in 24 of 37 patients (64.9\%), and 3-year angiography results showed occlusion in 24 of 25 patients (96\%). In conclusion, flow diversion is a safe and effective treatment for carotid-ophthalmic aneurysms in carefully selected patients. The risk of adverse visual outcomes is low, and most aneurysms progress to complete occlusion.
\end{abstract}

ABBREVIATION: PED = Pipeline Embolization Device

$F^{\prime}$ low-diverting stents work by directing blood flow away from the aneurysm into the parent vessel, leading to stasis of blood flow within the aneurysm, thrombosis, and, ultimately, complete exclusion of the aneurysm from circulation via endothelial proliferation along the struts of the device. ${ }^{1-3}$ Initial preclinical studies suggested that branch vessels covered by the device remain patent because the flow gradient at the branch vessel takeoff inhibits endothelial proliferation. ${ }^{2-5}$ In practice, flow diverters have been shown to lead to aneurysm occlusion rates ranging from $69 \%-94 \%$ at 6 months, increasing to $86.8 \%-95 \%$ at 1 year. $^{6-10}$ These initial series also reported a wide range of postprocedure morbidity and mortality up to $19 \% .^{6-10}$ Recently, several series have been published on the specific treatment of paraclinoid aneurysms with the Pipeline Embolization Device (PED; Covidien, Irvine, California) and Surpass Device (Stryker Neurovascular, Kalamazoo, Michigan), reporting complete or near-complete occlusion rates of 75\%-92.1\% at final angiographic follow-up with very low rates of postprocedure morbidity. ${ }^{11-14}$ Many of these series were relatively small, with short angiographic follow-up,

Received November 25, 2015; accepted after revision March 23, 2016.

From the Departments of Neurologic Surgery (A.M.B., R.C.P., G.L.) and Radiology (W.B., H.C., D.F.K., G.L.), Mayo Clinic, Rochester, Minnesota.

Please address correspondence to Waleed Brinjikji, MD, Mayo Clinic, Department of Radiology, 200 First St SW, Rochester, MN 55905; e-mail: brinjikji.waleed@mayo.edu; @wbrinjikji

http://dx.doi.org/10.3174/ajnr.A4835 and included vastly diverse aneurysms with a common denominator of involvement of the paraclinoid ICA. In this study, we reported on a large series of patients with carotid-ophthalmic artery aneurysms, focusing on periprocedural complications as well as mid- and long-term angiographic and clinical outcomes, including visual outcomes.

\section{MATERIALS AND METHODS \\ Patient Population}

Consecutive prospectively collected data on 175 patients evaluated for treatment with PED or, more recently, with Surpass flow diversion were retrospectively analyzed. Patients with carotidophthalmic artery aneurysms were identified and analyzed. Carotid-ophthalmic aneurysms were defined as those aneurysms arising from the proximal supraclinoid ICA at the takeoff of the ophthalmic artery with a superior orientation of the aneurysm sac. Information prospectively collected as part of an internal quality assurance project included patient demographics; aneurysm location, classification, and size; symptomatic or asymptomatic status; type and number of devices used; adjunctive coiling; periprocedural technical and clinical complications; length of hospital stay; and angiographic and clinical follow-up.

\section{Procedure Details}

Patients undergoing placement of the PED were premedicated with aspirin and clopidogrel for a minimum of 5 days, and the device was placed while the patient was under full anticoagulation 
(activated clotting time of 250-300 seconds). After the procedure, patients were maintained on dual antiplatelet therapy for 3 months. After 3 months, clopidogrel was discontinued and aspirin was continued indefinitely. The antiplatelet regimen was the same in all patients. No patient underwent testing for clopidogrel response except for the lone patient treated with the Surpass device who underwent the genetic test for CYP219 as part of the prospective study under which they were treated. All of the procedures were performed with the patient under general endotracheal anesthesia. A bi- or triaxial access technique was used to obtain distal access past the segment of the vessel with the targeted aneurysm. PEDs were sized to match the maximum diameter of the target vessel. At the discretion of the operators, 1 or multiple devices were used to maximize the chance of complete aneurysm occlusion and/or to ensure adequate coverage of the aneurysm neck and of a segment of parent artery proximal and distal to it (usually at least $5 \mathrm{~mm}$ ). DSA was performed at 2 frames per second before and after placement of the flow diverter. The lone patient treated with the Surpass device was treated in accordance with the Surpass Study Group protocol, ${ }^{11}$ which was functionally similar to the operative technique for placement of the PED.

\section{Study Outcomes}

Studied outcomes included new visual symptoms (including vision loss and cranial nerve palsy), angiographic occlusion, patency of the ophthalmic artery at previous angiographic followup, perioperative complications, delayed rupture, postoperative stroke and intraparenchymal hemorrhage, and long-term clinical outcomes. All angiographic outcomes were assessed by 1 of 3 senior neurointerventionalists/endovascular neurosurgeons.

\section{Statistical Analysis}

No comparative statistical analysis was performed. Continuous variables are reported as mean and standard deviation. Categoric variables are reported as $n(\%)$. All analyses were performed by using JMP 10.0 (SAS Institute, Cary, North Carolina).

\section{RESULTS}

We evaluated 50 aneurysms in 48 patients. Flow diversion was attempted but not deployed in 4 patients ( $8 \%$ ) because of vessel tortuosity in 3 and aneurysm perforation in 1. In total, 46 carotidophthalmic aneurysms were treated in 44 patients, of whom 2 were treated for mirror aneurysms. The mean patient age was $52 \pm 14$ years, and 41 aneurysms (93\%) were found in women. Recurrence after previous non-stent-assisted coiling in patients with prior SAH was the presenting symptom in 4 of 46 aneurysms (8.7\%). Of all 46 aneurysms, 10 (21.7\%) were symptomatic unruptured aneurysms (including 5 causing vision loss or diplopia) and $32(69.6 \%)$ were asymptomatic unruptured aneurysms.

Of the 46 aneurysms, 24 (52\%) were $10 \mathrm{~mm}$ or smaller (range, $3.5-10 \mathrm{~mm}), 21(45.7 \%)$ were large $(10-25 \mathrm{~mm})$, and $1(2.3 \%)$ was giant $(25 \mathrm{~mm})$. Twelve $(26.1 \%)$ of the aneurysms had been previously coiled and were treated with the PED for aneurysm recurrence or as a planned staged procedure. One aneurysm was treated with the Surpass device and 45 were treated with PED. Most aneurysms (32 [69.6\%]) were treated with 1 device, 9
(19.6\%) were treated with 2 devices, and $5(10.8 \%)$ were treated with 3 devices.

The mean clinical follow-up was $29 \pm 22$ months (range, $0-65$ ) and no patient was lost to clinical follow-up. At 12 days, 1 patient with a 21-mm aneurysm died of a delayed distal intraparenchymal hemorrhage not related to aneurysm rupture (procedure related mortality, 2.2\%), and 3 patients died of newly diagnosed (after the treatment) metastatic cancer at a mean of 40.7 months (range, 31-53 months). There were no delayed aneurysm ruptures. At 3 months, 1 patient experienced transient peripheral vision loss, possibly related to ipsilateral embolism from the device based upon MRI, which showed several small foci of restricted diffusion. She did not experience permanent vision loss. At 3 and 6 months after PED placement, 2 patients experienced possible amaurosis fugax that resolved after reestablishing dual antiplatelet therapy. The ophthalmic artery remained patent in all these patients. No other ophthalmologic complications were noted, and aside from the patient who suffered distal intraparenchymal hemorrhage, no other patient suffered a permanent neurologic deterioration because of the immediate or delayed effect of the procedure.

Among the 46 aneurysms, 37 (80.4\%) had 6-month angiographic follow-up, which showed complete occlusion in 24 (64.9\%) and persistent filling in $13(35.1 \%)$ based on strict angiographic criteria. Exclusion from 6-month angiography was found for the following reasons: death (1 patient), and refusal (2 patients). Six patients have not had angiographic follow-up due to the fact that they were less than 6 months out from the procedure at the time of this study. At 1 year, 29 of these 37 aneurysms (78.4\%) were completely occluded and 8 (21.6\%) showed persistent filling. At 3-year follow-up, 24 of 25 aneurysms (96\%) were occluded (Figure). No aneurysms shown to be occluded were found to have recanalized on later angiography. Among patients with angiographic follow-up, the ophthalmic artery was patent in $29(78.4 \%)$. Among the 8 patients in whom ophthalmic artery occlusion was noted, all had reconstitution of the ophthalmic artery through collaterals. In 7 patients, this occurred through external carotid artery collaterals, and in 1 patient, it occurred through the inferolateral trunk.

\section{DISCUSSION}

Our study of 44 patients with 46 ophthalmic segment aneurysms treated with flow diversion demonstrated high rates of angiographic occlusion with low rates of clinical adverse events, which included worsening of visual function. Rates of complete occlusion at 6 months, 1 year, and 3 years were $65 \%, 78 \%$, and $96 \%$, respectively. Only 1 patient experienced procedure-related morbidity or mortality, and no patients had permanent loss of visual function after treatment of ophthalmic segment aneurysms. Of 37 aneurysms that had 6-month angiography, there were 8 cases of ophthalmic artery occlusion after treatment, which were all asymptomatic. These findings are important because they suggest that flow diversion of ophthalmic segment aneurysms is safe and effective. In our opinion, flow diversion is now the treatment of choice for these aneurysms.

Several recent studies have reported series of patients with carotid-ophthalmic aneurysms treated by flow diversion. In a

AJNR Am J Neuroradiol 37:1866-69 Oct 2016 www.ajnr.org 

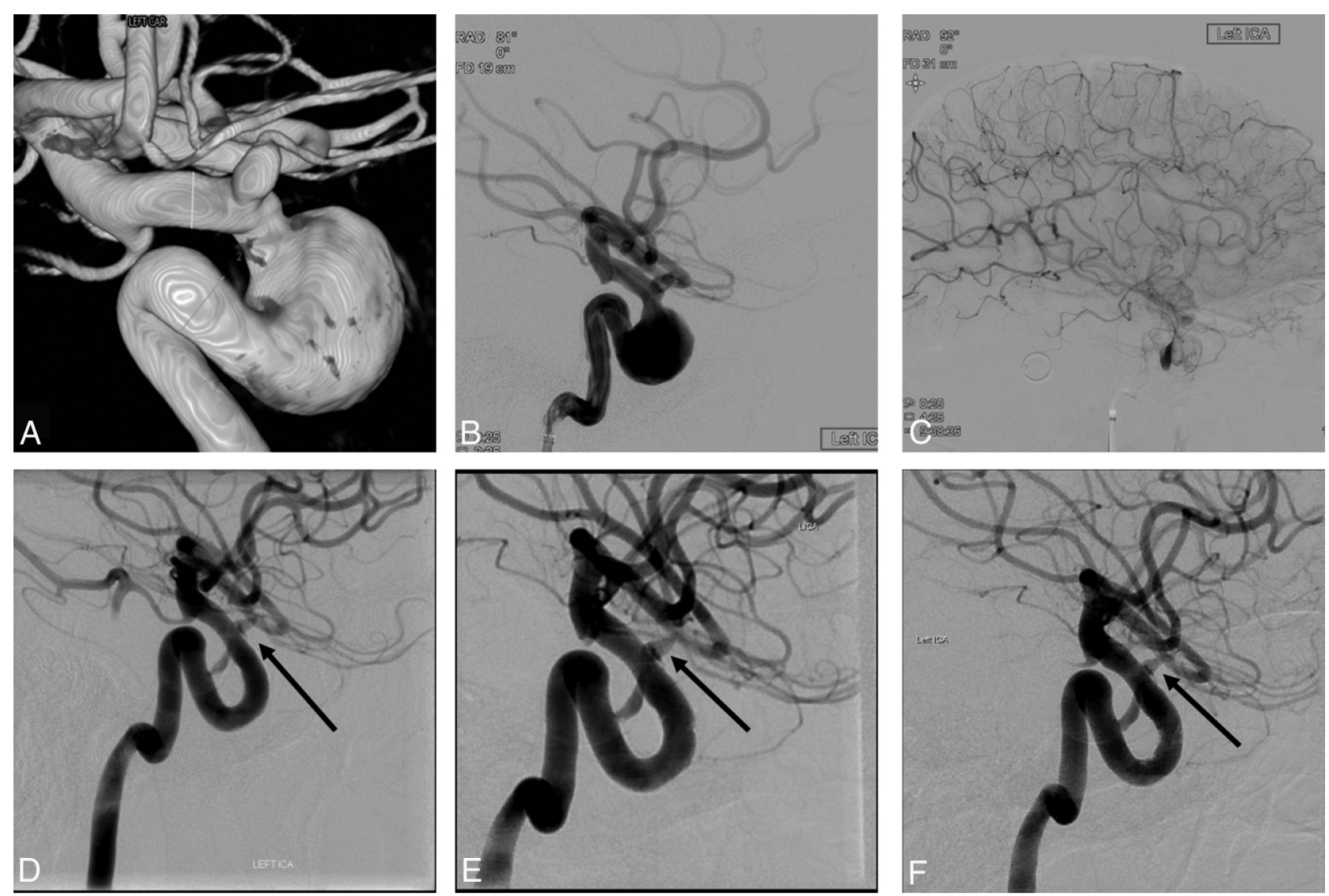

FIGURE. This 42-year-old woman underwent treatment with 3 PEDs for symptomatic left cavernous and ophthalmic segment aneurysms (shown in 3D rotation angiography, $A$ ). Immediate postdeployment early arterial lateral angiography shows both aneurysms filling ( $B$ ), while late arterial phase shows contrast stasis in both aneurysms $(C)$. After 6 months $(D), 1$ year $(E)$, and 3 years $(F)$, a lateral early arterial phase angiogram shows persistent ophthalmic aneurysm filling (black arrows), persistent ophthalmic artery filling, and a partially obliterated cavernous aneurysm with persistent filling through the posterior portion of the aneurysm. Because the aneurysm was nearly completely occluded at 3 years, a 5-year follow-up MRA was recommended for further follow-up.

subgroup analysis of the Pipeline for Uncoilable or Failed Aneurysms (PUFS) trial, Salhein et $\mathrm{al}^{15}$ examined the neuro-ophthalmologic outcomes of 98 patients with ICA aneurysms who had neuro-ophthalmologic follow-up. Of the 30 paraophthalmic segment aneurysms treated in this study, 8 presented with visual field or cranial nerve deficits, and 7 patients reported improvement in symptoms with treatment. There were no cases of worsening of visual field or cranial nerve deficits among paraophthalmic aneurysms in this study. Similar results have been reported in other large series of paraophthalmic aneurysms receiving flow-diverter treatment. ${ }^{11,13}$ Likewise, in our series of 44 patients with 46 aneurysms, no patients experienced visual worsening after flow-diverter treatment. A recent international retrospective review of aneurysms treated with flow diversion revealed that complications were more likely in aneurysms larger than $10 \mathrm{~mm}$ and among those in the posterior circulation. ${ }^{16}$ The lone death in our series occurred in a patient with a $21-\mathrm{mm}$ aneurysm.

In general, complete or near-complete occlusion rates after flow-diverter treatment are on the order of $90 \%$ and rates of neurologic complications are low. In our series of 46 ophthalmic segment aneurysms, we saw a progressive increase in the rate of complete occlusion over time, starting with an occlusion rate of $64.9 \%$ at 6 months that increased to $96 \%$ at 3 years. There was only 1 death related to the procedure. ${ }^{6}$
Similar to prior studies, we found very few instances of ophthalmic artery occlusion after placement of a flow diverter across the ophthalmic artery ostium. In a series of 95 patients in which the ophthalmic artery was covered by at least 1 flow diverter, Chalouhi et $\mathrm{al}^{17}$ found that the ophthalmic artery remained patent in nearly $95 \%$ of patients. Puffer et $\mathrm{al}^{18}$ found that the ophthalmic artery was patent in over $80 \%$ of patients after placement of a PED across its ostium. In our study, the ophthalmic artery was occluded in $21.6 \%$ of patients, and in no patient did this result in any new visual symptoms. Ophthalmic artery occlusion after placement of flow diverters across the origin of the artery is more likely to occur if patients have robust collaterals. In patients with inadequate collaterals, the ophthalmic artery stays open akin to important perforating vessels covered by these devices. In such cases, the pressure gradient across the artery (present because of the lack of important collaterals) maintains the patency of the vessel. Because occlusion of the ophthalmic artery occurs almost exclusively in patients with adequate collaterals, patients do not experience symptoms related to occlusion.

Other treatment options for ophthalmic segment aneurysms include microsurgical clipping and coiling with or without stent assistance. Complex ophthalmic segment aneurysms can be treated microsurgically with acceptable rates of complete occlusion (53\%), but the complexity of the surgical procedure may put 
the patient at risk of worsened visual symptoms postoperatively (with up to $21 \%$ of patients with preoperative visual symptoms having postoperative worsening in some series). ${ }^{19}$ Conventional endovascular coiling for ophthalmic segment aneurysms carries low risk based on published series (1.4\% morbidity, $0 \%$ mortality), but $12 \%$ of patients treated via conventional endovascular coiling required retreatment. ${ }^{20,21}$

\section{Limitations}

Our study is limited by the retrospective nature of the review, despite the prospectively maintained data base. The data base used for this study included patients treated with flow diversion over several years, and procedural techniques as well as aneurysm morphology deemed amenable to flow diversion have likely changed over that time. It is unclear what effect these changes would have on the analysis, but this still should be noted. Visual field testing was not performed in all patients, and thus, true deficits may be underrepresented. Finally, the 1 patient treated with the Surpass device precludes flow-diverter comparison. Despite these limitations, our series provides a contemporary snapshot of results for a specific subset of aneurysms (true carotid-ophthalmic aneurysms) in an institution where flow diversion has been considered the treatment of choice since its inception.

\section{CONCLUSIONS}

Endovascular flow diversion is a viable treatment option for ophthalmic segment aneurysms, resulting in a high rate of complete or near-complete occlusion and a low rate of complications (specifically, no permanent visual field deficits). Further studies examining neuro-opthalmalolgic outcomes after flow-diverter treatment of paraophthalmic aneurysms would be helpful to confirm these findings.

Disclosures: David F. Kallmes_UNRELATED: Board Membership: GE Healthcare (Cost effectiveness board)*; Consultancy: Medtronic, ${ }^{*}$ Comments: Planning and implementing clinical trials; Grants/Grants Pending: Microvention, ${ }^{\star}$ Medtronic, ${ }^{*}$ Codman, ${ }^{*}$ Surmodics, ${ }^{*}$ Sequent, ${ }^{*}$ Neurosigma, ${ }^{*}$ Comments: Preclinical research and clinical trials; Travel/Accommodations/Meeting Expenses Unrelated to Activities Listed: Medtronic, ${ }^{*}$ Comments: Presentation at FDA panel meeting. Giuseppe Lanzino-UNRELATED: Consultancy: Covidien/Medtronic. * *Money paid to the institution.

\section{REFERENCES}

1. D'Urso PI, Lanzino G, Cloft HJ, et al. Flow diversion for intracranial aneurysms: a review. Stroke 2011;42:2363-68 CrossRef Medline

2. Fang S, Lanzino G. Paraclinoid aneurysms: is there a new endovascular standard? Neurol Res 2014;36:314-22 CrossRef Medline

3. Wakhloo AK, Tio FO, Lieber BB, et al. Self-expanding nitinol stents in canine vertebral arteries: hemodynamics and tissue response. AJNR Am J Neuroradiol 1995;16:1043-51 Medline

4. Kallmes DF, Ding YH, Dai D, et al. A new endoluminal, flow-disrupting device for treatment of saccular aneurysms. Stroke 2007;38: 2346-52 CrossRef Medline

5. Trager AL, Sadasivan C, Seong J, et al. Correlation between angio- graphic and particle image velocimetry quantifications of flow diverters in an in vitro model of elastase-induced rabbit aneurysms. J Biomech Eng 2009;131:034506 CrossRef Medline

6. Becske T, Kallmes DF, Saatci I, et al. Pipeline for uncoilable or failed aneurysms: results from a multicenter clinical trial. Radiology 2013; 267:858-68 CrossRef Medline

7. Lubicz B, Collignon L, Raphaeli G, et al. Pipeline flow-diverter stent for endovascular treatment of intracranial aneurysms: preliminary experience in 20 patients with 27 aneurysms. World Neurosurg 2011; 76:114-19 CrossRef Medline

8. Lylyk P, Miranda C, Ceratto R, et al. Curative endovascular reconstruction of cerebral aneurysms with the Pipeline embolization device: the Buenos Aires experience. Neurosurgery 2009;64:632-42; discussion 642-43 CrossRef Medline

9. Nelson PK, Lylyk P, Szikora I, et al. The Pipeline embolization device for the intracranial treatment of aneurysms trial. AJNR Am J Neuroradiol 2011;32:34-40 CrossRef Medline

10. Szikora I, Berentei Z, Kulcsar Z, et al. Treatment of intracranial aneurysms by functional reconstruction of the parent artery: the $\mathrm{Bu}$ dapest experience with the Pipeline embolization device. AJNR Am J Neuroradiol 2010;31:1139-47 CrossRef Medline

11. Wakhloo AK, Lylyk P, de Vries J, et al. Surpass flow diverter in the treatment of intracranial aneurysms: a prospective multicenter study. AJNR Am J Neuroradiol 2015;36:98-107 CrossRef Medline

12. Moon K, Albuquerque FC, Ducruet AF, et al. Treatment of ophthalmic segment carotid aneurysms using the Pipeline embolization device: clinical and angiographic follow-up. Neurol Res 2014;36: 344-50 CrossRef Medline

13. Zanaty M, Chalouhi N, Barros G, et al. Flow-diversion for ophthalmic segment aneurysms. Neurosurgery 2015;76:286-89 CrossRef Medline

14. Burrows AM, Cloft H, Kallmes DF, et al. Periprocedural and midterm technical and clinical events after flow diversion for intracranial aneurysms. J Neurointerv Surg 2015;7:646-51 CrossRef Medline

15. Sahlein DH, Fouladvand M, Becske T, et al. Neuroophthalmological outcomes associated with use of the Pipeline embolization device: analysis of the PUFS trial results. J Neurosurg 2015;123:897-905 CrossRef Medline

16. Kallmes DF, Hanel R, Lopes D, et al. International retrospective study of the Pipeline embolization device: a multicenter aneurysm treatment study. AJNR Am J Neuroradiol 2015;36:108-15 CrossRef Medline

17. Chalouhi N, Daou B, Kung D, et al. Fate of the ophthalmic artery after treatment with the Pipeline embolization device. Neurosurgery 2015;77:581-84; discussion 584 CrossRef Medline

18. Puffer RC, Kallmes DF, Cloft HJ, et al. Patency of the ophthalmic artery after flow diversion treatment of paraclinoid aneurysms. J Neurosurg 2012;116:892-96 CrossRef Medline

19. Mattingly T, Kole MK, Nicolle D, et al. Visual outcomes for surgical treatment of large and giant carotid ophthalmic segment aneurysms: a case series utilizing retrograde suction decompression (the "Dallas technique"). J Neurosurg 2013;118:937-46 CrossRef Medline

20. Lai LT, Morgan MK. Outcomes for unruptured ophthalmic segment aneurysm surgery. J Clin Neurosci 2013;20:1127-33 CrossRef Medline

21. Yadla S, Campbell PG, Grobelny B, et al. Open and endovascular treatment of unruptured carotid-ophthalmic aneurysms: clinical and radiographic outcomes. Neurosurgery 2011;68:1434-43; discussion 1443 CrossRef Medline 